\title{
ANTIDANDRUFF ACTIVITYOF EXTRACTS FROM KAFFIR LIME (Citrus hystrix DC.) PREPARED BY DIFFERENT SOLVENTS
}

\author{
Lisawati Tanzil, Latirah, Priyanto Dwi Nugroho \\ Jurusan Analisa Farmasi dan Makanan, Politeknik Kesehatan Kemenkes Jakarta II, \\ J1. Raya Ragunan No.29C Pasar Minggu, DKI Jakarta, Kode Pos 12540 \\ E-mail: priyantodwinugroho@poltekkesjkt2.ac.id
}

\begin{abstract}
Pytiriasiscapitis or dandruff is a condition of exofoliate peeling of the stratum corneum layer in the scalp. There are some factors that suspected to caused dandruff such as increased production of sebum, sensitivity individual against the sebum and microbiota activity in scalp, i.eMalasseziafurfur, Malassezia globosa, Pytirosporumovale, and Candida albicans. Therefore, treatment of dandruff is aimed to reduced sebum on the scalp and inhibit the growth of yeast population that causes dandruff. The juice of kaffir lime fruit (Citrus hystrix DC.) has been used by Indonesian people for tradisional therapy of dandruff. This study thas been conducted to find out antidandruff activities of $M$. furfur from kaffir lime fruit juice, peel, and leaves of kaffir lime tree extracted by ethanol, ethyl acetat, and n-hexan solvents. Antifungal activitiesis measured by inhibition zones using well diffusion agar methods. All citrus extracts showed antifungal activities against M. furfur with ethyl acetat solvent indicated the highest antidandruff activities, then followed by n-hexan, and ethanolicsolvent; although ethyl acetat and n-hexan was not significantly different ( $>$ >0.05).Leaves extract showed highest inhibition activities, then followed by fruit juice and peel extract, although leaves and fruit juice extracts was not significantly different ( $p>0.05$ ).Part of the plant citrus consist of a alkaloid, saponin, tannin, phenolic, flavonoid, terpenoid, glikosida, and steroid. Antifungal activities suspected of phenolic, flavonoid, and terpenoid compounds. These results suggested that kaffir lime are effective against dandruff microbial and has potential as a herbal shampoo for dandruff treatment.
\end{abstract}

Keywords: antidandruff, kaffir lime, solvents

\section{AKTIVITAS ANTIKETOMBE EKSTRAK JERUK PURUT MENGGUNAKAN BEBERAPA JENIS PELARUT}

\begin{abstract}
ABSTRAK
Pytiriasiscapitisatau lebih dikenal sebagai ketombe, merupakan suatu kondisi eksfoliasi atau pengupasan berlebih pada lapisan stratum korneum di kulit kepala.Beberapa faktor yang diduga memacu timbulnya ketombe, antara lain: peningkatan produksi sebum, sensitivitas individu terhadap sebum dan aktivitas mikrobiota kulit kepala, sepertiMalassezia furfur, M. globosa.,Pytirosporumovale dan Candida albicans. Karena itu, pengobatan ketombe ditujukan untuk mengurangi sebum pada kulit kepala dan menghambat pertumbuhan populasi khamir penyebab ketombe.Air perasan buah jeruk purut (Citrus hystrixDC.) telah digunakan secara tradisional untuk mengatasi ketombe. Telah dilakukan penelitian untuk mengetahui aktivitas antifungi penyebab ketombe $M$. furfurmenggunakan metode difusi agar terhadap ekstrak air perasan buah, kulit buah dan daun jeruk purut dengan pelarut etanol, etil asetat, dan n-heksan.Seluruh ekstrak; ekstrak etanol, etil asetat, dan n-heksan dari air perasan buah, kulit buah, dan daun jeruk purut memiliki aktivitas penghambatan terhadap jamur penyebab ketombe $M$. furfur.Seluruh ekstrak jeruk purut mampu menghambat pertumbuhan $M$. furfur.Ekstrak etil asetat memberikan aktivitas penghambatan tertinggi, kemudian ekstrak n-heksan dan etanol; walaupun penghambatan oleh ekstrak etil asetat dan n-heksan berbeda tidak nyata ( $p>0.05)$.Ekstrak daun memiliki daya antifungal tertinggi diikuti oleh ekstrak air perasan buah dan ekstrak kulit buah; daya antifungal ekstrak daun dan air perasan berbeda tidak nyata.Seluruh bagian jeruk purut yang diteliti mengandung alkaloid, saponin, tanin, fenol, flavonoid, terpenoid, glikosida, and steroid.Senyawa fenol, flavonoid, dan terpenoid diduga sebagai antifungal. Penelitian ini menunjukkan jeruk memiliki potensi dikembangkan sebagai bahan aktif shampoo herbal antiketombe.
\end{abstract}

Kata kunci: antiketombe, jeruk purut, pelarut ekstraksi 


\section{PENDAHULUAN}

Pytiriasiscapitisatau lebih dikenal sebagai ketombe, merupakan suatu kondisi eksfoliasi atau pengupasan berlebih pada lapisan stratum korneum di kulit kepala.Ketombe umumnya terdapat pada bagian area belakang kepala, dengan gejala berupa munculnya sisik berwarna keputihan dan timbul rasa gatal (1).Misery (1) juga melaporkan bahwa $20.7 \%$ pria dan $12.8 \%$ wanita menderita ketombe dari 1703 subyek penelitian di negara Perancis. Studi epidemiologi kejadian ketombe di Indonesia belum banyak dilaporkan.

Beberapa faktor yang diduga memacu timbulnya ketombe, antara lain: produksi sebum yang meningkat akibat hiperaktivitas dari kelenjar sebaseus, sensitivitas individu terhadap sebum dan aktivitas mikrobiota kulit kepala, serta perubahan dinamika populasi mikrobiota kulit kepala (2). Populasi khamir Malasseziafurfur.,M. globosa, Pytirosporu movale dan Candida albicans meningkat nyata pada individu yang berketombe (3). Karena itu, pengobatan ketombe ditujukan untuk mengurangi sebum pada kulit kepala dan menghambat pertumbuhan dan aktivitas populasi khamir penyebab ketombe (4).

Tanaman jeruk purut (Citrus hystrix DC.) merupakan salah satu jenis tanaman yang mudah tumbuh, dan banyak tersebar di Indonesia. Air perasan buah jeruk purut telah digunakan secara turun temurun oleh masyarakat Indonesia untuk mengatasi ketombe. Ekstrak metanol dan ekstrak diklormetan buah jeruk purut $400 \mu \mathrm{g}$ dilaporkan mampu menghambat pertumbuhan khamir penyebab ketombe C. albicans(5). Bagian kulit buah jeruk purut ternyata memiliki daya anti mikrob yang lebih kuat dibandingkan dengan buah jeruk purut (6).

Potensi tanaman jeruk purut sebagai antifungi, sangat menarik untuk diteliti dan dikembangkan menjadi formula dan produk sampo anti ketombe herbal. Harga jeruk purut yang cukup murah serta kemudahan memperoleh bahan baku jeruk purut juga menjadi salah satu pertimbangan memilih tanaman ini, karena termasuk salah satu tanaman asli di Indonesia.

\section{METODE PENELITIAN}

\section{Penyiapan Simplisia dan Ekstrak}

Sampel daun dan buah jeruk purut diperoleh dari sentra perkebunan jeruk purut di Kecamatan Ngunut Kabupaten Tulungagung Jawa Timur. Sampel daun dan buah dipilih menggunakan metode purposive sampling dengan kriteria warna, bentuk, dan ukuran yang sama. Tanaman jeruk purut dideterminasi/identifikasi untuk memastikan nama jenisnya di Herbarium Bogoriense, bidang Botani Pusat Penelitian Biologi Lembaga Ilmu Pengetahuan Indonesia (LIPI) Bogor.

Daun jeruk purut dipisahkan dari pengotornya, dicuci dengan air mengalir dan diangin-anginkan sampai kering, kemudian dibuat serbuk dengan ukuran 40 mesh.Buah jeruk purut dicuci dengan air mengalir, dikupas dan diiris tipis-tipis.Bagian buah diperas airnya, kemudian kulit buah diserbukkan dengan ukuran 40 mesh.

Seluruh simplisia dan air perasan jeruk purut dimaserasi dengan pelarut etanol $96 \%$, n-heksan dan etil asetat selama 4x24 jam. Ekstrak kemudian dikentalkan dengan rotary evaporator pada suhu $50{ }^{\circ} \mathrm{C}$.

Ekstrak pekat selanjutnya dianalisis kandungan fitokimia secara visual dan daya penghambatan khamir penyebab ketombe secara difusi agar.Seluruh analisis dilakukan dengan tiga kali ulangan.

\section{Penapisan Fitokimia Ekstrak}

Penapisan senyawa bioaktif ekstrak jeruk purutdilakukan berdasarkan Harbone (7). Uji penapisan senyawa bioaktif dilakukan dengan tiga kali ulangan. 
Uji Steroid: ekstrak sebanyak $0.5 \mathrm{~mL}$ dicampurkan dengan $2 \mathrm{~mL}$ asam asetat dan 2 $\mathrm{mL}$ asam sulfat pekat. Diamati terbentuknya warna hijau atau kebiruan. Terbentuknya warna hijau atau biru menunjukkan adanya kandungan senyawa steroid; Uji Terpenoid: ekstrak sebanyak $5 \mathrm{~mL}$ dicampurkan dengan 2 $\mathrm{mL}$ kloroform dan $3 \mathrm{~mL}$ asam sulfat pekat. Diamati terbentuknya warna cokelat kemerahan. Terbentuknya warna cokelat kemerahan menunjukkan adanya kandungan senyawa terpenoid; Uji Tannin: ekstrak sebanyak 0.5 gram dicampurkan dengan aquades sebanyak $20 \mathrm{~mL}$. Campuran kemudian dididihkan selama lima menit. Campuran kemudian didinginkan dan ditambahkan $5 \% \quad \mathrm{FeCl}_{3}$ sebanyak dua tetes. Terbentuknya endapan berwarna kehijauan menunjukkan adanya kandungan senyawa tannin; Uji Flavonoid: ekstrak sebanyak $2 \mathrm{~mL}$ dicampurkan dengan $2 \mathrm{~mL}$ natrium hidroksida 40\%. Terbentuknya warna kuning menunjukkan adanya kandungan senyawa flavonoid; Uji Alkaloid: Asam pikrat sebanyak satu gram dicampurkan dengan ekstrak sebanyak $2 \mathrm{~mL}$. Terbentuknya warna jingga menunjukkan adanya kandungan senyawa alkaloid; Uji Saponin: ekstrak sebanyak $1 \mathrm{~mL}$ dimasukkan ke dalam tabung reaksi $15 \mathrm{~mm}$, kemudian ditambahkan akuades sebanyak 1 mL.Campuran ekstrak dengan akuades kemudian dikocok kuat selama 2 menit. Terbentuknya busa menunjukkan adanya kandungan senyawa saponin; Uji Fenol: ekstrak sebanyak $2 \mathrm{~mL}$ dicampurkan dengan $5 \% \mathrm{FeCl}_{3}$ sebanyak 2 $\mathrm{mL}$. Terbentuknya warna hijau kebiruan menunjukkan senyawa fenol;Uji Glikosida: ekstrak sebanyak $0.5 \mathrm{~mL}$ dicampurkan dengan asam asetat glasial sebanyak $2 \mathrm{~mL}$, kemudian ditambahkan satu tetes $5 \% \mathrm{FeCl}_{3}$. Asam sulfat pekat sebanyak $2 \mathrm{~mL}$ ditambahkan ke dalam campuran.Terbentuknya warna cokelat pada batas fase kedua cairan menunjukkan adanya kandungan senyawa glikosida.

\section{Aktivitas Anti Fungi Penyebab Ketombe}

Aktivitas anti fungi ekstrak daun, buah, dan kulit buah $C$. hystrixDC.dilakukan menggunakan difusi agar dengan metode sumur. Fungi uji yang digunakan adalah khamir $M$. furfur dan $P$. ovale.Biakan uji merupakan isolat patogen penyebab ketombe yang diperoleh dari Bagian Parasitologi Fakultas Kedokteran Universitas Indonesia.

Karakterisasi parsial untuk verifikasi biakan uji meliputi uji katalase, glukosa, laktosa, dan manitol.Metode difusi agar menggunakan khamir uji dengan jumlah masing-masing $1.0 \times 10^{6} \mathrm{CFU} \mathrm{mL}^{-1}$.Media yang digunakan yakni agar-agar Sabouraud Dextrose (SD) (Merck).Ketocenazol $15 \mu \mathrm{g}$ digunakan sebagai antibiotik pembanding dan kontrol positif.Kontrol negatif menggunakan pelarut yang digunakan yakni Dimethyl Sulfoxide (DMSO).Pengujian dilakukan dengan tiga kali ulangan.

Aktivitas anti fungi suatu senyawa dapat terlihat nyata menggunakan metode difusi agar (Kirby Bauer) (8).Zona hambat yang terbentuk mengindikasikan adanya aktivitas anti fungi di dalam suatu senyawa uji.Daya aktivitas anti fungi ditunjukkan dengan ukuran diameter zona hambat yang terbentuk.

Pengujian aktivitas anti fungi metode sumur dilakukan dengan prosedur sebagai berikut: media agar SD yang telah berisi khamir uji dilubangi (diameter $6 \mathrm{~mm}$ ) dan dimasukkan masing-masing zat uji sebanyak $20 \mu \mathrm{L}(10 \%$, 20\%, dan 30\%). Seluruh Petri dimasukkan ke dalam refrigerator selama 20 menit $\left(8{ }^{\circ} \mathrm{C}\right)$, lalu diinkubasi selama 7 hari pada suhu $37{ }^{\circ} \mathrm{C}$.Zona hambat yang terbentuk diukur ( $\mathrm{mm})$.

\section{Analisis Data}

Seluruh data penelitian dianalisis secara statistik menggunakan piranti lunak minitab17.Analisis ANOVA satu arah digunakan untuk mengetahui perbedaan rata- 
rata diameter zona hambat antar kelompok ekstrak, dan kelompok khamir uji.

\section{HASIL DAN PEMBAHASAN}

Daun dan buah yang ditelitimerupakan bagian dari tanaman jeruk purut (Citrus hystrix DC.), berdasarkan surat sertifikat hasil determinasi/identifikasi tumbuhan yang dikeluarkan oleh LIPI dengan nomor surat No.

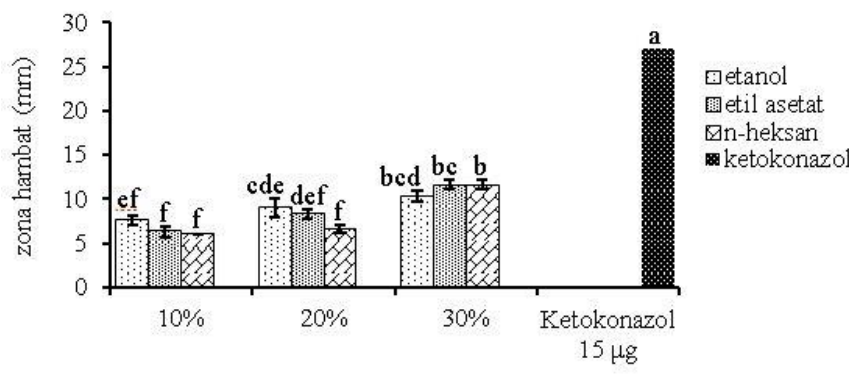

Gambar 1 Diameter zona hambat ( $\mathrm{mm}$ ) ekstrak air perasan buah jeruk purut dengan berbagai konsentrasi pelarut terhadap $M$. furfur

huruf berbeda menyatakan beda nyata $(p<0.05)$

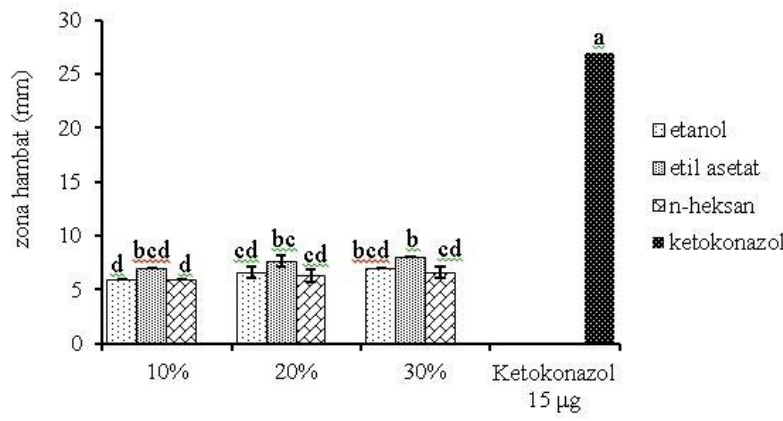

Gambar 3 Diameter zona hambat ( $\mathrm{mm}$ ) ekstrak kulit buah jeruk purut dengan berbagai konsentrasi pelarut terhadap $M$. furfur

huruf yang berbeda menyatakan beda nyata $(p<0.05)$

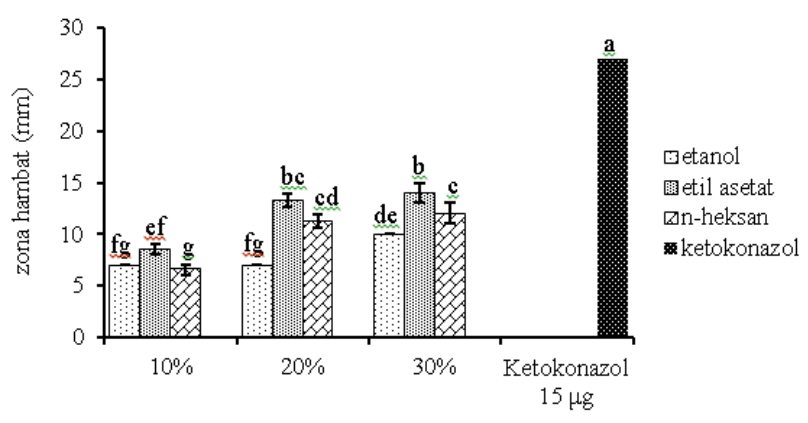

Gambar 2 Diameter zona hambat ( $\mathrm{mm}$ ) ekstrak daun jeruk purut dengan berbagai konsentrasi pelarut terhadap $M$. furfur

huruf yang berbeda menyatakan beda nyata $(p<0.05)$
1905/IPH.1.01/If.07/VIII/2017.

Seluruh ekstrak kental dari simplisia daun, kulit buah, dan air perasan buah dianalisis daya penghambatan terhadap pertumbuhan jamur penyebab ketombe; $M$. furfur dan $P$. ovale.Ekstrak etil asetat dari seluruh ekstrak yang diuji diketahui memiliki penghambatan yang lebih kuatdaripada ekstrak etanol dan n-heksanterhadap $M$. furfur(Gambar 1, 2, dan 3), namun seluruh ekstrak tidak mampu menghambat pertumbuhan jamur $P$. ovale (data tidak ditampilkan).

Daya hambat ekstrak kasar pada penelitian ini diukur berdasarkan zona hambat (mm); semakin besar zona mengindikasikan daya hambat yang semakin kuat.Metode sumur agar-agar difusi dipilih karena paling sensitiv untuk menilai potensi antibakteri/anti fungi dari ekstrak kasar bahan alam (9).

Penghambatan jamur penyebab ketombe dari ekstrak air perasan dan daun jeruk purut berbeda tidak nyata $(\mathrm{p}>0.05)$, dan kedua ekstrak berbeda nyata dengan ekstrak kulit buah $(\mathrm{p}<0.05)$.Ekstrak dari daun jeruk purut memiliki daya hambat yang lebih kuat dibandingkan dengan ekstrak air perasan buah, dan kulit buah jeruk purut, sedangkan zona hambat ekstrak kulit buah yang paling kecil (Gambar 2). Pemilihan pelarut yang tidak tepat untuk ekstraksi senyawa bioaktif dari kulit buah diduga kuat yang memicu zona hambat menjadi lebih kecil dibandingkan kedua bagian tanaman yang lain.

Semakin tinggi konsentrasi ekstrak diduga menaikan daya hambat pertumbuhan fungi. Namun demikian pada Gambar 2 dan 3ditunjukan bahwa, antara konsentrasi 20\% dengan $30 \%$ ekstrak etil asetat\& n-heksan daun \& kulit buah menunjukkan perbedaan yang tidak bermakna ( $>0.05)$. Zona hambat seluruh ekstrak terhadap $M$. furfurmasih lebih rendah dibandingkan kontrol positif; ketokonazol. Hal ini diduga karena ekstrak yang diuji merupakan ekstrak kasar, bukan senyawa tunggal yang telah diketahui 
memiliki potensi sebagai antifungi. Mekanisme penghambatan fungi oleh ketokonazolberdasarkan penghambatan sintesis ergosterol; senyawa yang berperan dalam permeabilitas membran plasma sel fungi (10).Namun demikian seluruh ekstrak etil asetat, etanol, dan n-heksanpada konsentrasi $30 \%$ dari daun dan air perasan buah jeruk purut aktif menghambat pertumbuhan jamur penyebab ketombe $M$. furfur. Diameter zona hambat $<9 \mathrm{~mm}$, inaktif; 9-12 mm, aktif lemah; 13-18 mm, aktif kuat; $>18 \mathrm{~mm}$, aktif kuat(11).Ekstrak etil asetat $30 \%$ dari daun memiliki aktivitas tertinggi dan tergolong aktif kuat.

Ekstrak etil asetat memiliki efek penghambatan tertinggi, diduga karena pelarut etil asetat yang bersifat semi polar.Aktivitas antimikrob ekstrak etil asetat yang lebih kuat daripada ekstrak etanol dan metanol juga telah dilaporkan sebelumnya (12).Pelarut yang bersifat semi polar mampu menarik/ melarutkan senyawa bioaktif pada tanaman yang bersifat polar dan nonpolar, sehingga diduga lebih banyak jenis senyawa bioaktif yang terkandung pada ekstrak etil asetat.

Tabel 1Kandungan senyawa bioaktif dari ekstrak etil asetat jeruk purut

\begin{tabular}{lccc}
\hline \multirow{2}{*}{ Senyawa } & \multicolumn{3}{c}{ Jenis ekstrak etil asetat } \\
\cline { 2 - 4 } & $\begin{array}{c}\text { Air } \\
\text { perasan }\end{array}$ & Daun & $\begin{array}{c}\text { Kulit } \\
\text { buah }\end{array}$ \\
\hline Alkaloid & + & + & + \\
Saponin & + & + & + \\
Tanin & + & + & + \\
Fenolik & + & + & + \\
Flavonoid & + & + & + \\
Triterpenoid & + & + & + \\
Steroid & - & + & + \\
Glikosida & + & + & + \\
\hline
\end{tabular}

Seluruh ekstrak etil asetat dari air perasan buah, daun, dan kulit buah memiliki kandungan senyawa bioaktif yang hampir sama. Hanya ekstrak etilasetat-air perasan buah yang tidak mengandung senyawa steroid, seperti ditunjukkan pada Tabel 1. Walaupun jenis kandungan senyawa bioaktif yang hampir sama, namun efek terhadap pertumbuhan jamur berbeda. Hal ini diduga karena konsentrasi senyawa bioaktif yang terkandung tidak sama; penelitian ini tidak menganalisis konsentrasi senyawa bioaktif.

Ekstrak etil asetat kulit buah jeruk purut telah diketahui memiliki daya hambat spektrum luas (menghambat bakteri Gram positif dan Gram negatif) juga mampu menghambat pertumbuhan jamur patogen $A$. fumigatusdan $S$. cerevisiae (12).Minyak atsiri jeruk purut diduga kuat yang berperandalam penghambatan mikrob. Minyak atsiri yang bersifat nonpolarakan mudah larut dalam pelarut non polar seperti etil asetat. Komponen utama minyak atsirijeruk purut yakni monoterpenoid hidrokarbon dan monoterpenoid oksigen (13).Senyawa golongan fenolik dan flavonoid dari jeruk purut diketahui juga sebagai antimikrob(14).

\section{SIMPULAN DAN SARAN}

Seluruh ekstrak; ekstrak etanol, etil asetat, dan n-heksan dari air perasan buah, kulit buah, dan daun jeruk purut memiliki aktivitas penghambatan terhadap jamur penyebab ketombe $M$. furfur.Ekstrak daun jeruk purut dan air perasan buah memiliki potensi antiketombe yang berbeda tidak nyata ( $p>0.05$ ).Etil asetat merupakan pelarut terbaik yang mampu memberikan zona hambat tertinggi, meskipunberbeda tidak nyata ( $p>0.05)$ pada konsentrasi 30\% dengan ekstrak n-heksan dan etanol kulit buah serta air perasan buah.Berdasarkan analisis kandungan ekstrak etil asetat, diketahui bahwa senyawa terpenoid, fenolik, dan flavonoid diduga kuat yang menghambat pertumbuhan jamur penyebab ketombe $M$. furfur.

Kajian lebih lanjut terhadap fraksi etil asetat diperlukan karena potensinya sebagai bahan aktif shampo herbal antiketombe.

Lisawati Tanzil., et al 


\section{DAFTAR PUSTAKA}

1. Misery L, RahhaliN, Duhamel A, Taieb C. 2013. Epidemiology of dandruff, scalp pruritus and associated symptoms. ActaDermVenereol. 93: 80-82.

2. Xu Z, Wang Z, Yuan C, Liu X, Yang F, Wang T, Wang J, Manabe $\mathrm{K}$, Qin $\mathrm{O}$, Wang Q, Zhang Y, Zhang M. 2016. Dandruff is associated with the conjoined interactions between host and microorganisms. Nature. 6:24877.

3. Rudramurthy SM, Honnavar P, Dogra PS, Yegneswaran PP, Handa S, Chakrabarti A. 2014. Association of Malassezia species with dandruff. Indian J Med Res. 13 (9): 431-437.

4. Schwart JR, Messenger AG, Tosti A, Todd G, Hordinsky M, Hay RJ, Wang X, Zachariae C, Kerr KM, Henry JP, Rust RC, Robinson MK. 2012. A Comprehensive pathophysiology of dandruff and seborrheicdermatitis towards a more precise definition of scalp health. ActaDermVenereol . 92: 1-10.

5. Chowdhury A, Alam MA, Rahman MS, Hossain MA, Rashid MA. 2009. Antimicrobial, antioxidant and cytotoxic activities of Citrus hystrix DC. fruits. Dhaka Un J Pharm Sci. 8(2): 177-180.

6. Ajithkumar IN, Panneerselvam R. 2012. Effect of Citrus hystrix and Citrus limon extracts on antibacterial activity against human pathogens. As Pacific J Trop Biomed.7(4): 1-4.

7. Harborne AJ. 1998. Phytochemical Methods A Guide to Modern Techniques of Plant Analysis. Springer. New York.

8. Deviha MS, Pavithram KS. 2015. Antifungal activity by ethanolic extracts of medicinal plants against Malasseziafurfur : A potential application in the treatment of Dandruff. Int $\mathrm{J}$ Pharmtech Res. 8(3): 440-444.

9. Valgas C, de Souza SM, Smania EFA, SmaniaJr A. Screening methods to determine antibacterial activity of natural products. BJM. 2007; 38:369-80.

10. Faergemann J, Borgers M, Degreef H. A new ketoconazole topical gel formulation in seborrhoeic dermatitis: an update review of the mechanism. Expert OpinPharmacother. 2007; 8(9):1365-71.

11. de Almeida Alves TM, Silva AF, Brandão M, Grandi TSM, SmãniaEF, SmaniaJr A, Zani CL. MemsInstOswaldo Cruz. 2000; 95(3):367-73.

12. Yasurin P. Review: antimicrobial properties of common herbs and spices used in Thai cooking. Res J Pharm BiolChem Sci. 2015; 6(1):48-57.

13. Warsito, Noorhamdani, Sukardi, Suratmo. Aktivitas antioksidan dan antimikroba minyak jeruk purut (Citrus hystrix DC.)dan komponen utamanya. J Enviroment Engineer Suistain Tech. 2017; 4(1):13-8.

14. Klangpetch W, Phromsurin K, Hannarong $\mathrm{K}$, Wicaphon J, Rungchang S. Antibacterial and antioxidant effects of tropical citrus peel extracts to improve the shelf life of raw chicken drumettes. Int Food Res J. 2016; 23(2): 700-7. 